\title{
First report on echinocandin resistant Polish Candida isolates
}

\author{
Martyna Mroczyńska and Anna Brillowska-Dąbrowska® \\ Gdańsk University of Technology, Faculty of Chemistry, Department of Molecular Biotechnology and Microbiology, Gdańsk, Poland
}

\begin{abstract}
Purpose: Candida spp. are ranked as one of the four major causative agents of fungal infections. The number of infections caused by Candida species resistant to fluconazole, which is applied as the first line drug in candidiasis treatment, increases every year. In such cases the application of echinocandin is necessary. Echinocandin susceptibility testing has become a routine laboratory practice in many countries due to the increasing frequency of clinical failures during treatment with these drugs. Methods: We performed anidulafungin, micafungin and caspofungin susceptibility testing according to the microdilution broth method on 240 Candida isolates collected in Polish hospitals. Results: We identified 12 isolates resistant to all echinocandins within 240 examined isolates. Moreover, 6 of the examined samples were identified as rare Candida species and among them we observed very high echinocandin MIC values. Conclusion: Our research proves that in Poland there is a problem of echinocandin resistance. Moreover, we identified two species of Candida which are rare causative agents of human infections, and there was no reported incidence of such infections in Poland until now.
\end{abstract}

Key words: Candida infections, echinocandin resistance, minimal inhibitory concentration, C. palmioleophila, C. inconspicua

Received: 31 May, 2019; revised: 16 August, 2019; accepted: 22 August, 2019; available on-line: 12 September, 2019

$\square$ e-mail: annbrill@pg.edu.pl

Abbreviations: AND, anidulafungin; C., Candida; CLSI, Clinical and Laboratory Standards Institute procedure; CSP, caspofungin, GRASO, CHROMagar Candida; ITS, Internal Transcribed Spacer; MCF, micafungin; MIC, Minimal Inhibitory Concentration

\section{INTRODUCTION}

Candida spp. are ranked as the fourth leading causative agent of fungal infections in intensive care units (Sanguinetti et al., 2015). About 90\% of these infections are caused by Candida (C.) albicans, C. glabrata, C. parapsilosis, C. tropicalis, and C. krusei (Sanguinetti et al., 2015). So far, the most prevalent pathogen during candidaemia that was isolated has been $C$. albicans. According to the clinical practice guidelines, fluconazole and echinocandin are the first line drugs in empiric therapy in case of Candida infections (Pappas et al., 2015). The echinocandin group consists of three compounds: anidulafungin (AND), caspofungin (CSP) and micafungin (MCF). The choice of the appropriate antimycotics is related to the patient's condition, as well as the type of infection. However, an increase in the number of fungal infections caused by non-albicans species, such as C. glabrata or C. krusei, showing natural resistance to fluconazole (Choi et al., 2009), is the reason for the application of echinocandins. Infections caused by $C$. glabrata are now the second most common cause of candidaemia in North America and Europe (Pappas et al., 2015), and result in increased mortality rates in patients with candidaemia (Cornely et al., 2014). The frequency of echinocandin resistance among Candida spp. differs depending on the species, the region of infection and the patient (Grossman et al., 2014). Studies conducted in different countries have shown a variety of $C$. albicans resistant to echinocandin. According to Castanheira et al.'s research, echinocandin resistance among C. albicans is at approximately 3\% (Castanheira et al., 2010). However, echinocandin resistance among C. glabrata seems to be a serious problem. Studies conducted from 2001 to 2010 had shown an increase in resistance from $2-3 \%$ to more than 13\% among the C. glabrata strains (Perlin, 2015).

A report from 2015 made in Italy in accordance with the Clinical and Laboratory Standards Institute procedure (CLSI) has shown the resistance to AND (2.7\%), CSP $(16.2 \%)$ and MCF $(13.5 \%)$ among C. glabrata isolates (Montagna et al., 2015). So far, there has been no information about clinical isolates being resistant to echinocandin in Poland. The frequency of non-albicans infections in Poland is increasing. The mortality of patients with candidiasis was $8.5 \%$, in 118 clinical cases of infections in Polish hospitals (Dzierzanowska-Fangrat et al., 2014). Research conducted in 2013 at 20 Polish hospitals based on a two years period, reported 302 cases of candidaemia. The highest number of infections was found in intensive care $(30.8 \%)$ and surgical $(29.5 \%)$ units, whereas hematological units reached $15.9 \%$, and the lowest number of infections was seen in neonatological units $(4.6 \%)$. The most frequent isolated species was C. albicans $(50.96 \%)$. The frequency of C. krusei and C. tropicalis was at $24 \%$ and $18 \%$, respectively, in the hematology units. The distribution of C. glabrata and C. parapsilosis was at $14.1 \%$ and $13.1 \%$, and there was no statistically significant differences between the departments (Nawrot et al., 2013). The results, published in 2008, 2012, 2014 and 2017, had shown that according to the results of E-tests there were no any non-Candida isolates resistant to caspofungin and micafungin (Szymankiewicz \& Dancewicz, 2008; Wieczorek et al., 2008; Kurnatowska et al., 2012; Gołaś et al., 2014; Sulik-Tyszka et al., 2017).

\section{MATERIALS}

In this study we identified and examined AND, CSP and MCF susceptibility of 240 Candida isolates, collected in four Polish hospitals in Gdansk, Szczecin, Warsaw and Wroclaw, between the years of 2008 to 2012. The isolates originated from a variety of clinical specimens, for example isolated from swabs of the mouth, throat, faeces, urine, blood, and bronchopulmonary lavage fluid. 
Table 1. In vitro echinocandin susceptibility test results of 240 isolates of Candida spp.

Cumulative no. of isolates susceptible at a MIC $[\mathrm{mg} / \mathrm{l}]$ of:

\begin{tabular}{|c|c|c|c|c|c|c|c|c|c|c|c|c|c|}
\hline \multicolumn{4}{|c|}{ MIC breakpoint ${ }^{18}[\mathrm{mg} / \mathrm{l}]$} & \multicolumn{10}{|c|}{137 isolates of C. albicans } \\
\hline & $\mathrm{S}$ & 1 & $\mathrm{R}$ & $\leq 0.008$ & 0.016 & 0.031 & 0.063 & 0.125 & 0.25 & 0.5 & 1 & 2 & $\geq 4$ \\
\hline AND & $\leq 0.25$ & 0.5 & $\geq 1$ & 79 & 23 & 14 & 11 & 4 & 1 & 2 & 3 & - & - \\
\hline MCF & $\leq 0.25$ & 0.5 & $\geq 1$ & 28 & 69 & 22 & 9 & 3 & - & 3 & 3 & - & - \\
\hline CSP & $\leq 0.25$ & 0.5 & $\geq 1$ & 2 & 24 & 34 & 28 & 33 & 7 & 3 & 5 & - & 1 \\
\hline
\end{tabular}

\begin{tabular}{|c|c|c|c|c|c|c|c|c|c|c|c|c|c|}
\hline \multicolumn{4}{|c|}{ MIC breakpoint ${ }^{18}$ [mg/l] } & \multicolumn{10}{|c|}{72 isolates of C. glabrata } \\
\hline & $\mathrm{S}$ & I & $\mathrm{R}$ & $\leq 0.008$ & 0.016 & 0.031 & 0.063 & 0.125 & 0.25 & 0.5 & 1 & 2 & $\geq 4$ \\
\hline AND & $\leq 0.12$ & 0.25 & $\geq 0.5$ & 3 & 10 & 32 & 13 & 5 & - & 4 & 4 & 1 & - \\
\hline MCF & $\leq 0.12$ & 0.25 & $\geq 0.5$ & 7 & 31 & 19 & 3 & 3 & 1 & - & 7 & 1 & - \\
\hline CSP & $\leq 0.06$ & 0.12 & $\geq 0.25$ & - & 2 & 7 & 22 & 22 & 10 & 2 & 5 & - & 2 \\
\hline
\end{tabular}

\begin{tabular}{|c|c|c|c|c|c|c|c|c|c|c|c|c|c|}
\hline \multicolumn{4}{|c|}{ MIC breakpoint ${ }^{18}[\mathrm{mg} / \mathrm{l}]$} & \multicolumn{10}{|c|}{17 isolates of C. krusei } \\
\hline & S & 1 & $\mathrm{R}$ & $\leq 0.008$ & 0.016 & 0.031 & 0.063 & 0.125 & 0.25 & 0.5 & 1 & 2 & $\geq 4$ \\
\hline AND & $\leq 0.25$ & 0.5 & $\geq 1$ & - & 2 & 3 & 11 & - & - & - & - & - & 1 \\
\hline MCF & $\leq 0.25$ & 0.5 & $\geq 1$ & - & 1 & - & - & 12 & 3 & - & - & - & 1 \\
\hline CSP & $\leq 0.25$ & 0.5 & $\geq 1$ & - & - & - & - & - & 1 & 2 & 13 & - & 1 \\
\hline
\end{tabular}

\begin{tabular}{|c|c|c|c|c|c|c|c|c|c|c|c|c|c|c|}
\hline \multicolumn{4}{|c|}{ MIC breakpoint ${ }^{18}[\mathrm{mg} / \mathrm{l}]$} & \multicolumn{11}{|c|}{8 isolates of C. parapsilosis } \\
\hline & $\mathrm{S}$ & 1 & $\mathrm{R}$ & $\leq 0.008$ & 0.016 & 0.031 & 0.063 & 0.125 & 0.25 & 0.5 & 1 & 2 & 4 & 8 \\
\hline AND & $\leq 2$ & 4 & $\geq 8$ & - & - & - & - & 1 & - & 2 & 4 & - & - & 1 \\
\hline MCF & $\leq 2$ & 4 & $\geq 8$ & - & - & - & - & 1 & - & - & 6 & - & - & 1 \\
\hline CSP & $\leq 2$ & 4 & $\geq 8$ & - & - & - & - & 1 & - & 2 & 1 & 1 & 2 & 1 \\
\hline
\end{tabular}

6 other isolates (5 C. palmioleophila and 1 C. inconspicua)

\begin{tabular}{|c|c|c|c|c|c|c|c|c|c|c|}
\hline \multirow{4}{*}{ Lack of MIC breakpoint } & 0.008 & 0.016 & 0.031 & 0.063 & 0.125 & 0.25 & 0.5 & 1 & 2 & $\geq 4$ \\
\hline & 2 & - & - & - & - & - & 2 & - & - & 2 \\
\hline & 2 & - & - & - & - & - & 1 & 1 & - & 2 \\
\hline & - & 2 & - & - & - & - & - & 1 & - & 3 \\
\hline
\end{tabular}

\section{METHODS}

All isolates were cultured on CHROMagar Candida (GRASO) medium and incubated for $48 \mathrm{~h}$ at $35^{\circ} \mathrm{C}$. For the species identification, ITS1, 5.8S RNA, ITS4 (White et al., 1990) regions was amplified and then sequenced. DNA extractions were performed according to an earlier described procedure (BrillowskaDabrowska et al., 2013). 2x Master Mix HighGC (A\&A Biotechnology) was applied for all of the PCR assays performed. PCR products were purified (Cleanup, A\&A Biotechnology) and sequenced (Macrogen). 
Table 2. In vitro echinocandin susceptibility test results of 6 rare isolates of Candida spp.

\begin{tabular}{|c|c|c|c|c|c|}
\hline \multirow{2}{*}{ Species } & \multirow{2}{*}{ Number of isolates } & \multirow{2}{*}{ Place of isolation } & \multicolumn{3}{|c|}{ MIC value [mg/l] of: } \\
\hline & & & AND & MCF & CSP \\
\hline C. inconspicua & 1444 W & - & 4 & 4 & 4 \\
\hline C. palmioleophila & $4 \mathrm{~W}$ & - & 4 & 4 & 4 \\
\hline C. palmioleophila & $368 \mathrm{~S}$ & sputum & 1 & 0.5 & 1 \\
\hline C. palmioleophila & $370 \mathrm{G}$ & blood & 0.008 & 0.008 & 0.016 \\
\hline C. palmioleophila & $377 \mathrm{G}$ & liver cysts & 0.008 & 0.008 & 0.016 \\
\hline C. palmioleophila & $405 \mathrm{G}$ & mouth & 0.5 & 0.5 & 4 \\
\hline
\end{tabular}

${ }^{1}$ W, clinical sample isolated from a patient at Wroclaw hospital; ${ }^{2} \mathrm{~S}$, clinical sample isolated from a patient at Szczecin hospital; ${ }^{3} \mathrm{G}$, clinical sample isolated from a patient at Gdansk hospital

Sequence analysis was performed with VectorNTI (Informax).

Minimal Inhibitory Concentrations (MIC) were determined by broth microdilution and the results were read visually following $24 \mathrm{~h}$ incubation, as the lowest concentration of the drug that caused a complete growth inhibition. Also, Candida albicans ATCC 90028 and Candida krusei ATCC 6258 strains were used as controls. All tests were performed in triplicates and in case of discrepancies they were repeated. AND (Pfizer), CSP (Sigma-Aldrich), MCF (Astellas) were obtained as a standard powder.

\section{RESULTS}

Among 240 Candida samples, by sequencing an rRNA fragment we identified: 137 C. albicans, 72 C. glabrata 17 C. krusei, 8 C. parapsilosis and 6 strains belonging to two rare Candida species: 5 C. palmioleophila and 1 C. inconspicua strain. CHROMagar Candida correctly identified 93.4\% C. albicans, $97.2 \%$ C. glabrata, 80\% C. krusei strains. C. palmioleophila developed a turquoise color on CHROMagar, while $C$. inconspicua colonies were pink to violet.

Results of three echinocandins susceptibility examination tests are presented in Table 1. Among 137 C. albicans isolates, as many as 3 had shown a significant decrease in susceptibility to AND, 6 to CSP and 3 to MCF (minimal inhibitory concentration value for all echinocandins $\geq 1 \mathrm{mg} / \mathrm{L}$ ); 2 isolates were intermediately resistant to AND, 3 to CSP, and 3 to MCF. In general, only $3 / 137(2.2 \%)$ isolates of $C$. albicans were resistant to all echinocandins.

Out of 72 C. glabrata isolates, as many as 9 had shown a significant decrease in susceptibility to AND, 19 to CSP and 8 to MCF (MIC values: $\geq 0.5 \mathrm{mg} / 1, \geq 0.5 \mathrm{mg} / 1$, $\geq 0.25 \mathrm{mg} / 1$, respectively). Only 1 isolate was intermediately resistant to $\mathrm{MCF}$ and 22 to CSP, (MIC value $\geq 0.125 \mathrm{mg} / \mathrm{l} ; \geq 0.25 \mathrm{mg} / \mathrm{l}$. Only 7 isolates were resistant to all three echinocandins.

In the case of C. krusei we observed a decrease in CSP susceptibility of $14 / 17$ isolates. However, these isolates were sensitive to AND and MCF. According to the echinocandin mechanism of action and well known technical problems with establishing MIC for CSP, it is unlikely that such a large percentage of isolates would show resistance only to one antibiotic from this group. Thus, these C. krusei isolates were probably not resistant to echinocandins because they were neither resistant to AND nor MCF. We identified only 1 isolate which was resistant to three echinocandins (MICs value $\geq 4 \mathrm{mg} / \mathrm{L}$ for all echinocandins).

Among 8 C. parapsilosis we identified one resistant isolate to all echinocandins (MIC values $\geq 8 \mathrm{mg} / \mathrm{l}$ ).

The MIC values of rare species of Candida were very high, but there is no echinocandin breakpoint established for these species (probably due to the low frequency of occurrence). The MIC value $\geq 4$ was observed for one isolates of $C$. palmioleophila, and the same MIC value for the three echinocandin is exhibited by C. inconspicua. Two isolates of $C$. palmioleophila had MIC values $\leq 0.016 \mathrm{mg} / 1$. The two isolates had a different MIC value depending on the examined antimycotics. The results of echinocandin susceptibility testing of these rare Candida isolates are listed in Table 2.

\section{DISCUSSION}

Epidemiological studies on Candida infections are conducted in many countries (Choi et al., 2009). Various data are available on the prevalence of resistance to echinocandins among fungi of the Candida genus. These studies report that the occurrence of resistant isolates varies depending on the site of infection and the patient population. Previous epidemiological studies on resistance of Candida spp. in Poland are an insufficient source of data. There are two reports (Szymankiewicz \& Dancewicz, 2008; Wieczorek et al., 2008) from 2008 on caspofungin susceptibility testing performed with Etests on isolates collected in the Polish hospitals. All of the 29 and 93 examined Candida isolates were susceptible to echinocandins. Another two reports from 2012 and 2014 had shown that there were no resistant Candida isolates within the 10 and 150 specimens collected in the Polish hospitals (Kurnatowska et al., 2012; Gołaś et al., 2014). The latest echinocandin susceptibility testing was performed with E-tests in 2017. Only 46 isolates were examined and echinocandin resistance was not found (Sulik-Tyszka et al., 2017).

Our research has shown that the echinocandin resistance of Candida isolates is a problem in Poland, especially within non-albicans species $-9.7 \%$ C. glabrata isolates were echinocandins resistant $(7 / 72)$. Echinocandins susceptibility testing had shown that out of all the 240 isolates of Candida spp., $14(5.8 \%)$ were resistant to AND; $40(16.6 \%)$ to $\mathrm{CSP}$, and $13(5.4 \%)$ to MCF.

What is very interesting, we isolated 6 isolates belonging to two species that are rarely identified as a cause of human infections. C. inconspicua is described in the 
literature as a fluconazole resistant and amphotericin B susceptible and is isolated from immunocompromised patients (Baily et al., 1997; Sugita et al., 2004; Guitard et al., 2013; Majoros et al., 2005). We identified one isolate of $C$. inconspicua which was characterized by very high echinocandins MIC.

Out of 5 C. palmioleophila isolates, 3 were characterized by high echinocandins MIC value. According to a variety of data, C. palmioleophila could be resistant to fluconazole and susceptible to other antimycotics, e.g. echinocandins (Liu et al., 2017; Meletiadis et al., 2016), but there is also some information about elevated caspofungin MIC of C. palmioleophila (Brilhante et al., 2017). C. palmioleophila were found in animal microflora (Sokół et al., 2018) and there are only a few data available on $C$. palmioleophila as an etiological agent of human infections (Trouvé et al., 2017).

It should be emphasized that data on previous echinocandins exposure (type and duration of antifungal therapy of patients) of the isolates examined in our study are not available. However, this does not change the fact that we indicate the problem of echinocandin resistance in Poland. Moreover, as the number of infections caused by Candida species resistant to fluconazole which is applied as the first line drug in candidiasis treatment in Poland increases, the occurrence of echinocandins resistance within Candida isolates should be examined.

\section{Declaration of interest}

The authors report no conflicts of interest.

\section{Ethics approval}

This study was exempt for ethics board approval as patient-specific public health information was not collected.

\section{REFERENCES}

Baily GG, Moore CB, Essayag SM, de Wit S, Burnie JP, Denning DW (1997) Candida inconspicua, a fluconazole-resistant pathogen in patients infected with human immunodeficiency virus. Clin Infect Dis 25: 161-163

Brilhante RSN, Silva ALD, Monteiro FOB, et al (2017) Yeasts from Scarlet ibises (Eudocimus ruber): A focus on monitoring the antifungal susceptibility of Candida famata and closely related species. Med Mycol 55: 725-732. https://doi.org/10.1093/mmy/myw144

Brillowska-Dabrowska A, Michalek E, Saunte DM, Nielsen SS, Arendrup MC (2013) PCR test for Microsporum canis identification. Med Mycol 53: 576-579. https://doi.org/10.3109/13693780903531579

Castanheira M, Woosley LN, Diekema DJ, et al (2010) Low prevalence of fks1 hot spot 1 mutations in a worldwide collection of Candida strains. Antimicrob Agents Chemother 54: 2655-2659. https://doi. org/10.1128/AAC.01711-09

Choi HK, Jeong SJ, Lee HS, Chin BS, Choi SH, Han SH, Kim MS, Kim CO, Choi JY, Song YG, Kim JM (2009) Blood stream infections by Candida glabrata and Candida krusei: a single-center experience. Korean J Intern Med 24: 263-269. https://doi.org/10.3904/ kjim.2009.24.3.263

Clinical and Laboratory Standards Institute. Reference Method for Broth Dilution Antifungal Susceptibility Testing of Yeasts. Fourth Informational Supplement. CLSI document M27-S4 2012. Wayne PA: Clinical and Laboratory Standards Institute 2012.

Cornely OA, Vazquez J, Waele J, Betts R, Rotstein C, Nucci M, Pappas PG, Ullmann AJ (2014) Efficacy of micafungin in invasive candidiasis caused by common Candida species with special emphasis on non-albicans Candida species. Mycoses 57: 79-89. https://doi. org/10.1111/myc.12104

Dzierzanowska-Fangrat K, Romanowska E, Gryniewicz-Kwiatkowska J, Migdał M, Witulska K, Ryżko J, Kaliciński P, Książyk J, Nadkowska P (2014) Candidaemia in a Polish tertiary paediatric hospital, 2000 to 2010. Mycoses 57: 105-109. https://doi.org/10.1111/ myc. 12107

Gołaś M, Netsvyetayeva I, Sikora M, Piskorska K, Sulik-Tyszka B, Swoboda-Kopeć E (2014) Trends in antifungal susceptibility of Candida species - one year observation. Pol J Microbiol 63: 217-222
Grossman NT, Chiller TM, Lockhart SR (2014) Epidemiology of echinocandin resistance in Candida. Curr Fungal Infect Rep 8: 243-248. https://doi.org/10.1007/s12281-014-0209-7

Guitard J, Angoulvant A, Letscher-Bru V, L'Ollivier C, Cornet M, Dalle F, Grenouillet F, Lacroix C, Vekhoff A, Maury E, Caillot D, Charles PE, Pili-Floury S, Herbrecht R, Raffoux E, Brethon B, Hennequin C (2013) Invasive infections due to Candida norvegensis and Candida inconspicua: report of 12 cases and review of the literature. Med Mycol 51: 795-799. https://doi.org/10.3109/13693786.20 13.807444

Kurnatowska A, Kurnatowski P, Horwatt-Bożyczko E, Kurnatowska AJ (2012) Minimal inhibitory concentration (MIC) of caspofungin and itraconazole inhibiting growth of Candida strains calculated from the linear regression equation. Adv Med Sci 57: 148-151. https://doi.org/10.2478/v10039-012-0022-x.

Liu WL, Lai CC, Li MC, Wu CJ, Ko WC, Hung YL, Tang HJ, Hsueh PR (2017) Clinical manifestations of candidemia caused by uncommon Candida species and antifungal susceptibility of the isolates in a regional hospital in Taiwan, 2007-2014. J Microbiol Immunol. https:// doi.org/10.1016/j.jmii.2017.08.007

Majoros L, Kardos G, Szabó B, Sipiczki M (2005) Caspofungin susceptibility testing of Candida inconspicua: correlation of different methods with the minimal fungicidal concentration. Antimicrob Agents Chemother 49: 3486-3488. https://doi.org/10.1128/AAC.49.8.34863488.2005

Meletiadis J, Geertsen E, Curfs-Breuker I, Meis JF, Mouton JW (2016) In vitro activity of micafungin against common and rare Candida species with the EUCAST, CLSI and E-test method: Intra-and interlaboratory agreement. Antimicrob Agents Chemother 60: 6173-6178. https://doi.org/10.1128/AAC.01027-16

Montagna MT, Lovero G, Coretti C, Martinelli D, De Giglio O, Iatta R, Balbino S, Rosato A, Caggiano G (2015) Susceptibility to echinocandins of Candida spp. strains isolated in Italy assessed by European Committee for Antimicrobial Susceptibility Testing and Clinical Laboratory Standards Institute broth microdilution methods. BMC Microbiol 15: 106. https://doi.org/10.1186/s12866-015-0442-4

Nawrot U, Pajączkowska M, Fleischer M, Przondo-Mordarska H, Samet A, Piasecka-Pazik D, Komarnicka J, Sulik-Tyszka B, Swoboda-Kopeć E, Cieślik J, Mikucka A, Gospodarek E, Ozorowski T, Mól A, Tryniszewska E, Kłosowska W, Krawczyk M, Golec K, Szymaniak L, Giedrys-Kalemba S, Bilska I, Prawda-Zołotar J, Juszczyk-Grudzińska M, Wróblewska M, Burdynowski K (2013) Candidaemia in Polish hospitals-a multicentre survey. Mycoses 56: 576-581. https://doi.org/10.1111/myc.12077

Pappas PG, Kauffman CA, Andes DR, Clancy CJ, Marr KA, Ostrosky-Zeichner L, Reboli AC, Schuster MG, Vazquez JA, Walsh TJ, Zaoutis TE, Sobel JD (2015) Clinical practice guideline for the management of candidiasis: 2016 update by the Infectious Diseases Society of America. Clin Infect Dis 62: e1-e50. https://doi. org $/ 10.1093 / \mathrm{cid} /$ civ933

Perlin D (2015) Echinocandin Resistance in Candida. Clin Infect Dis 61: 612-617. https://doi.org/10.1093/cid/civ791

Sanguinetti M, Posteraro B, Lass-Flörl C (2015) Antifungal drug resistance among Candida species: mechanisms and clinical impact. $M y$ coses 5: 2-13. https://doi.org/10.1111/myc.12330

Sokół I, Gaweł A, Bobrek K (2018) The prevalence of yeast and characteristics of the isolates from the digestive tract of clinically healthy turkeys. Avian Dis 62: 286-290. https://doi.org/10.1637/11780121117-Reg.1

Sugita T, Takeo K, Ohkusu M, et al (2004) Fluconazole-resistant pathogens Candida inconspicua and C. norvegensis: DNA sequence diversity of the rRNA intergenic spacer region, antifungal drug susceptibility, and extracellular enzyme production. Microbiol Immunol 48: 761-766. https://doi.org/10.1111/j.1348-0421.2004.tb03602.x

Sulik-Tyszka B, Cieślik J, Niewiński G, Wróblewska M (2017) Epidemiological analysis and evaluation of in vitro susceptibility to micafungin of clinical strains of Candida spp. causing fungaemia in patients hospitalised in intensive care unit. Forum zakażeń 8: 157-161. (in Polish)

Szymankiewicz M, Dancewicz M (2008) In vitro activity of voriconazole and caspofungin against Candida spp. strains evaluated by E-test. Mikol Lek 15: 13-15 (in Polish)

Trouvé C, Blot S, Hayette MP, Jonckheere S, Patteet S, RodriguezVillalobos H, Symoens F, Van Wijngaerden E, Lagrou K (2017) Epidemiology and reporting of candidaemia in Belgium: a multicentre study. Eur J Clin Microbiol Infect Dis 36: 649-655. https://doi. org/10.1007/s10096-016-2841-3

White TJ, Bruns T, Lee S, Taylor JW (1990) Amplification and direct sequencing of fungal ribosomal RNA genes for phylogenetics. In PCR Protocols: A Guide to Methods and Applications. Academic Press, Inc., New York 18: 315-322. https://doi.org/ 10.3109/13693786.2012.755741

Wieczorek P, Sacha P, Źórawski M, Jakoniuk P, Tryniszewska E (2008) In vitro activity of caspofungin against strains of the genus Candida. Mikol Lek 15: 135-139 (in Polish) 